\title{
Nutritional status in heart failure patients throughout chronic kidney disease stages
}

\author{
López-Rodríguez Yadira ${ }^{1}$, Orea-Tejeda Arturo ${ }^{1}$, Castillo-Martínez Lilia ${ }^{1}$, \\ Delgado-Pérez David Alejandro ${ }^{1}$, Keirns-Davis Candace ${ }^{2}$, García-Castañeda Luis Roberto ${ }^{1}$, \\ Calvario-Monarca Elizabeth ${ }^{1}$, Dávila-Radilla Fernando ${ }^{1}$ \\ ${ }^{1}$ Heart Failure Clinic at Instituto Nacional de Ciencias Médicas y Nutrición “Salvador Zubirán”, México City, México \\ ${ }^{2}$ Massachusetts General Hospital Interpreter Services, Boston, MA 02114, USA
}

\section{Email address:}

cam7125@gmail.com (Castillo-Martínez L.)

\section{To cite this article:}

López-Rodríguez Yadira, Orea-Tejeda Arturo, Castillo-Martínez Lilia, Delgado-Pérez David Alejandro, Keirns-Davis Candace, GarcíaCastañeda Luis Roberto, Calvario-Monarca Elizabeth, Dávila-Radilla Fernando. Nutritional Status in Heart Failure Patients throughout Chronic Kidney Disease Stages. American Journal of Health Research. Vol. 2, No. 4, 2014, pp. 196-202.

doi: 10.11648/j.ajhr.20140204.25

\begin{abstract}
Background \& aims: Heart failure (HF) is associated with significant morbidity and mortality, the prognosis of heart failure is poor, especially with coexisting chronic kidney disease (CKD). However little is known about how HF and CKD together influence the nutritional status, so the main objective of this study was to assess nutritional status in patients with heart failure coexisting with stage 1-5 renal disease. Methods: This retrospective study included a total of 113 patients with HF and CKD that were classified into stages 1-5 according to the Kidney Disease Outcome Quality Initiative (K/DOQI) guidelines. The following characteristics were recorded: co-morbidities, New York Heart Association (NYHA) functional class, echocardiographic data, medication, and biochemical parameters (albumin, hemoglobin and electrolytes). Nutritional status was evaluated by bioimpedance vector analysis (BIVA) and subjective global assessment (SGA). Results: In the nutritional status evaluation by BIVA, $53.1 \%$ were cachectic, $23.9 \%$ obese and $21.12 \%$ normal. The prevalence of cachexia is higher with advancing stages of CKD, while hand grip strength, arm and waist circumferences decreased. In SGA $79.8 \%$ had a normal nutritional status, $16.8 \%$ mild malnutrition and $2.7 \%$ moderate-severe malnutrition. Hypoalbuminemia was presented in $22.5 \%$ of subjects, most commonly found in stages 1,4 and 5 ; the prevalence of anemia was $47.2 \%$ and also increased with advancing stages of CKD, showing a prevalence of $13.3 \%$ in stage 1 and $100 \%$ stage 5. Conclusions: The prevalence of cachexia was higher in stages 3-5 of CKD, mild to severe malnutrition in stages 4 and 5, and anemia in stage 5, so HF and advanced CKD are associated with deteriorating nutritional status.
\end{abstract}

Keywords: Bioimpedance Vector Analysis, Nutritional Status, Heart Failure, Chronic Kidney Disease

\section{Introduction}

The coexistence of heart failure (HF) and chronic kidney disease (CKD) result in an increased morbidity, mortality and healthcare-related costs compared to any of these organ failures alone; both HF and CKD share co-morbidities that complicate their evolution, regardless of the initial pathology. $(1,2)$

It is known that in HF, the nutritional status is affected by different factors such as decrease food ingestion secondary to anorexia and metabolic changes mediated by inflammatory and neurohormonal activation that includes, release of the tumor necrosis factor alpha $(\mathrm{TNF}-\alpha)$ and other cytokines that participate in the catabolism process, with subsequent loss of weight. (3) Inflammation and muscle wasting are also prevalent in patients with chronic kidney disease and worsen as kidney failure progress. (4)

However, little is known about how HF and chronic kidney disease together influence the nutritional status.(5) The Subjective Global Assessment (SGA) has been used to evaluate the nutritional status of chronic dialysis (6) and heart failure patients, (7) but SGA does not directly assess body hydration. In HF and CKD patients, the evaluation of nutritional status may be biased because of the changes in the body hydration. Indeed, at physical examination, the same soft tissue mass can be increased or decreased by 
different hydration levels. Piccoli et al have demonstrated that bioimpedance vector analysis (BIVA) has the potential for the combined evaluation of hydration and nutrition.(6) Thus, BIVA has been used as a method for nutritional assessment in different studies for the determination of body composition in patients with HF or CKD. $(8,9)$

The main objective of this study was to assess the nutritional status by BIVA and SGA in patients with heart failure and renal disease from stages 1-5 classification according to the Kidney Disease Outcome Quality Initiative (K/DOQI) guidelines.

\section{Patients and Methods}

Patients attended to the Heart Failure Clinic at the Instituto Nacional de Ciencias Médicas y Nutrición "Salvador Zubirán" (INCMNSZ) in Mexico City were studied retrospectively. They were considered eligible for study inclusion if they were $\geq 18$ years old and had a confirmed diagnosis of HF by echocardiogram, defined as systolic or diastolic HF, according to the ESC criteria (10) and CKD according to glomerular filtration rate measured by the modification of diet in renal disease equations (MDRD). Subjects were excluded in cases of pregnancy, enrollment in other clinical trials, cerebral vascular event or transient ischemic attack during the past 3 months before enrollment, malfunctioning cardiac valve, obstructive hypertrophic cardiomyopathy, non-corrected congenital heart disease, acute myocarditis and if they had been diagnosed rheumatoid arthritis, cancer, history of amputations or loss of one kidney. The present study was performed in accordance with the Declaration of Helsinki content and Good Clinical Practice Guidelines.

\subsection{Clinical and Body Composition Evaluation}

Co-morbidities, medical treatment, NYHA functional class assessment, heart rate, systemic pressure, signs and symptoms related to HF were recorded. All patients underwent a Doppler-echocardiography study using Hewlett Packard Sonos 5500 equipment with M-mode, two dimensional and Doppler images in parasternal long and short axis and two and four chamber apical views to assess the cardiac function. All these evaluations were performed by a cardiologist blinded to the study groups.

Weight, height, waist, hip and arm circumferences were measured in accordance with the Lohman (1991) manual reference of anthropometric standardization; all subjects wore light clothing and were barefoot. Body mass index was calculated by dividing the total body weight (kilograms) by the height squared (meters). The SGA was carried out using the protocol developed by Detsky et al. (11) It relies on the patient's history regarding weight loss, dietary intake, gastrointestinal symptoms, functional capacity, and physical signs of malnutrition (loss of subcutaneous fat or muscle mass, edema, ascites). Patients were evaluated by one operator and classified as (1) well nourished, (2) moderate or suspected malnutrition, and (3) severe malnutrition. Since subgroups were small, we only report the frequency of malnourished patients.

Handgrip strength was measured as indicator of muscle function using the Smedley Hand Dynamometer (Stoelting, Wood Dale, UK). Patients were instructed to apply as much handgrip pressure as possible by using their dominant hand. The measurements were repeated twice, and the highest score was recorded in kilograms. (12)

Whole-body bioelectrical impedance was measured in the morning using tetra polar and multiple-frequency equipment (BodyStat QuadScan 4000, Bodystat Ltd.; Isle of Man, UK). All measurements were made according to the tetra polar method reported in the existing literature. (13) The impedance values were obtained at frequencies of 5, 50, 100 , and $200 \mathrm{kHz}$. The $50 \mathrm{kHz}$ frequency was selected because it is the standard frequency used for bioelectrical impedance vector analysis to obtain resistance (R50) and reactance $(\mathrm{Xc50})$. Phase angles were obtained by the Bodystat ${ }^{\circledR}$ Phase Angle Software Program (version 1.0). Patients were classified according to their phase angle and $<4.2^{\circ}$ was considered high risk of malnutrition. (14) The $\mathrm{R} 50$ and $\mathrm{Xc50}$ were standardized for height $(\mathrm{H})$ to obtain the impedance vector $\mathrm{Z} / \mathrm{H}$, which is represented in the $\mathrm{RXc}$ graph (abscissa $\mathrm{R} / \mathrm{H}$, ordinate $\mathrm{Xc} / \mathrm{H})$. $(15,16)$ For the evaluation of the vector within groups, mean vector components $(\mathrm{R} / \mathrm{H}$ and $\mathrm{Xc} / \mathrm{H})$ were plotted on the genderspecific $50 \%, 75 \%$, and $95 \%$ tolerance ellipses calculated in the Mexican reference healthy population as an RXc graph. (17) The gender-specific RXc graph was divided into four sectors. Patients with vectors out of the $75 \%$ tolerance ellipse of the reference population at the lower right quadrant were classified as cachectic, at the lower left quadrant as obese.

The whole-body impedance ratio at $200 \mathrm{kHz}$ to that at 5 $\mathrm{kHz}(\mathrm{Z200/Z5)}$ was also obtained as an indicator of water distribution and total body water and extracellular water in liters and percentages were obtained.

\subsection{Biochemical Measures}

Blood samples were collected for determination of serum levels of glucose, creatinine, urea, urea nitrogen, albumin, hemoglobin, hematocrit, sodium, potassium, chloride, calcium, phosphorus and magnesium. Anemia was diagnosed from hemoglobin (women: $<12 \mathrm{~g} / \mathrm{dL}$, men $<14 \mathrm{~g} / \mathrm{dL}$ ) and hematocrit (women: $<35 \%$, men: $<42 \%$ ) and hypoalbuminemia with albumin levels $<3.5 \mathrm{~g} / \mathrm{dL}$.

Estimated glomerular filtration rate (eGFR) was calculated by the six-variable Modification of Diet in Renal Disease (MDRD) equation eGFRMDRD $=198 \times\left[_{\mathrm{SCr}}\right]^{-0.858}$ $\mathrm{x}[\mathrm{Age}]^{-0.167} \mathrm{x}[0.822$ if patient is female $] \mathrm{x}$ [1.178 if patient is black $] \times[\mathrm{SUN}]^{-0.293} \times[\mathrm{UUN}]^{+0.249} \cdot(18)$

The classification of stages of chronic kidney disease was made according to the Kidney Disease Outcome Quality Initiative (K/DOQI) guidelines in patients with kidney damage or decreased renal function during at least 3, classifying patients into five stages of CKD. (19) 


\subsection{Statistical Analysis}

All analyses were performed with commercially available software (SPSS 17.0 for Windows, SPSS, Inc., Chicago, IL, USA). Continuous variables were expressed as mean \pm standard deviation, and categorical variables were presented as absolute and relative frequencies. For the comparison of continuous variables among $\mathrm{K} / \mathrm{DOQI}$ stages, one-way analysis of variance (ANOVA) was used, and for categorical variables, the Pearson chi-square test was used. An analysis of covariance (ANCOVA) was made to control the difference in age between groups. A p value $<0.05$ was considered statistically significant.

\section{Results}

From 104 patients $(60.2 \%$ men) included in the present study, $18(15.9 \%)$ were classified as K/DOQI 1, $32(28.3 \%)$ as $\mathrm{K} / \mathrm{DOQI} 2,34(30.1 \%)$ as $\mathrm{K} / \mathrm{DOQI} 3,13(11.5 \%)$ as $\mathrm{K} / \mathrm{DOQI} 4$, and $16(14.2 \%)$ as K/DOQI 5.

The most frequent co morbidities were hypertension, type 2 diabetes, and ischemic heart disease, with no differences in prevalence among stages. The most common clinical signs were fatigue in stages 1 and fluid retention in stage 5 , and less frequently, decubitus intolerance in stages $1,2,4$ and 5, while in the stage 3 a lower prevalence was fluid retention was observed. Anorexia was present in 33\% $(n=15)$ of subjects, being higher in stage 4 with a prevalence of $46.2 \%$ and lower in stage 3 with a prevalence of $2.9 \%$. (Table 1 )

Table 1. Clinical and cardiologic data of patients with HF and CKD classified according to KDOQI stage

\begin{tabular}{|c|c|c|c|c|c|c|}
\hline Variable & $\begin{array}{l}\text { Stage } 1 \\
\text { GFR }(90-130 \mathrm{ml} / \mathrm{min}) \\
\mathrm{n}=9\end{array}$ & $\begin{array}{l}\text { Stage } 2 \\
\text { GFR }(60-89 \mathrm{ml} / \mathrm{min}) \\
\mathrm{n}=32\end{array}$ & $\begin{array}{l}\text { Stage } 3 \\
\text { GFR }(30-59 \mathrm{ml} / \mathrm{min}) \\
\mathrm{n}=34\end{array}$ & $\begin{array}{l}\text { Stage } 4 \\
\text { GFR }(15-29 \mathrm{ml} / \mathrm{min}) \\
\mathrm{n}=13\end{array}$ & $\begin{array}{l}\text { Stage } 5 \\
\text { GFR }(<15 \mathrm{ml} / \mathrm{min}) \\
\mathrm{n}=16\end{array}$ & p \\
\hline Male gender, n (\%) & $9(100)$ & $16(50)$ & $23(67.6)$ & $7(53.8)$ & $8(50)$ & 0.27 \\
\hline Age (year) & $53.05 \pm 17.59$ & $68.81 \pm 10.52$ & $68.82 \pm 13.44$ & $74.23 \pm 16.55$ & $47.06 \pm 22.15$ & $<0.0001$ \\
\hline Obesity, n (\%) & $6(66.7)$ & $12(37.5)$ & $12(35.3)$ & $1(7.7)$ & $4(25)$ & 0.08 \\
\hline Hypertension, n (\%) & $6(66.7)$ & $21(65.6)$ & $27(79.4)$ & $10(76.9)$ & $15(93.8)$ & 0.16 \\
\hline Diabetes, n (\%) & $5(55.6)$ & $16(50)$ & $16(46.2)$ & $5(31.3)$ & $5(31.3)$ & 0.81 \\
\hline $\begin{array}{l}\text { Cardiovascular } \\
\text { disease, } \mathrm{n}(\%)\end{array}$ & $4(44.4)$ & $15(46.9)$ & $18(52.9)$ & $8(61.5)$ & $6(37.5)$ & 0.62 \\
\hline Dyslipidemia, n (\%) & $3(33.3)$ & $13(40.6)$ & $11(32.4)$ & $3(23.1)$ & $3(18.8)$ & 0.56 \\
\hline $\begin{array}{l}\text { Hypothyroidism, } \mathrm{n} \\
(\%)\end{array}$ & 0 & $7(21.9)$ & $7(20.6)$ & $4(30.8)$ & $7(43.8)$ & 0.35 \\
\hline Dyspnea, n (\%) & $5(55.6)$ & $12(37.5)$ & $9(26.5)$ & $7(53.8)$ & $6(37.5)$ & 0.52 \\
\hline $\begin{array}{l}\text { Decubitus } \\
\text { intolerance, } \mathrm{n}(\%)\end{array}$ & $3(33.3)$ & $11(34.4)$ & $7(20.6)$ & $4(30.8)$ & $5(31.3)$ & 0.79 \\
\hline Fluid retention, n (\%) & $4(44.4)$ & $12(37.5)$ & $6(17.6)$ & $6(46.2)$ & $10(62.5)$ & 0.03 \\
\hline Fatigue, n (\%) & $9(100)$ & $19(59.4)$ & $16(47.1)$ & $9(69.2)$ & $8(50)$ & 0.11 \\
\hline Anorexia, n (\%) & $2(22.2)$ & $4(12.5)$ & $1(2.9)$ & $6(46.2)$ & $2(12.5)$ & 0.004 \\
\hline $\begin{array}{l}\text { Systolic blood } \\
\text { pressure (mmHg) }\end{array}$ & $118.88 \pm 17.63$ & $122.59 \pm 17.24$ & $121.29 \pm 18.79$ & $110.61 \pm 14.19$ & $146.25 \pm 26.80$ & $<0.0001$ \\
\hline $\begin{array}{l}\text { Diastolic blood } \\
\text { pressure }(\mathrm{mmHg})\end{array}$ & $73.33 \pm 11.18$ & $75.81 \pm 25.00$ & $70.58 \pm 11.01$ & $69.07 \pm 9.58$ & $85.62 \pm 13.14$ & 0.03 \\
\hline Heart rate (Lpm) & $70.00 \pm 13.11$ & $67.31 \pm 10.08$ & $69.26 \pm 12.95$ & $71.07 \pm 10.05$ & $74.12 \pm 10.66$ & 0.33 \\
\hline Ejection fraction (\%) & $40.77 \pm 17.77$ & $45.90 \pm 18.74$ & $47.38 \pm 17.41$ & $45.18 \pm 16.54$ & $55.26 \pm 9.63$ & 0.50 \\
\hline $\begin{array}{l}\text { Ventricular septum } \\
(\mathrm{mm})\end{array}$ & $12.66 \pm 2.17$ & $11.56 \pm 2.15$ & $11.36 \pm 1.90$ & $11.00 \pm 1.90$ & $13.40 \pm 3.52$ & 0.045 \\
\hline Posterior wall (mm) & $11.11 \pm 1.83$ & $11.78 \pm 2.97$ & $10.60 \pm 1.99$ & $10.75 \pm 1.81$ & $12.60 \pm 3.33$ & 0.05 \\
\hline $\begin{array}{l}\text { Left atrial diameter } \\
(\mathrm{mm})\end{array}$ & $46.88 \pm 4.56$ & $42.46 \pm 7.02$ & $42.21 \pm 8.06$ & $44.58 \pm 11.82$ & $43.80 \pm 7.74$ & 0.89 \\
\hline $\begin{array}{l}\text { Pulmonary Artery } \\
\text { Pressure (mmHg) }\end{array}$ & $55.42 \pm 16.42$ & $44.59 \pm 16.12$ & $42.44 \pm 16.65$ & $46.81 \pm 19.82$ & $40.53 \pm 14.57$ & 0.78 \\
\hline \multicolumn{7}{|l|}{ NYHA n (\%) } \\
\hline I & $2(25.0)$ & $19(59.4)$ & $23(67.6)$ & $4(30.8)$ & $7(43.8)$ & \\
\hline II & $4(50.0)$ & $12(37.5)$ & $9(26.5)$ & $5(38.5)$ & $6(37.5)$ & 0.10 \\
\hline III-IV & $2(25.0)$ & $1(3.1)$ & $2(5.9)$ & $4(30.8)$ & $3(18.8)$ & \\
\hline Beta blocker n (\%) & $8(89.9)$ & $30(93.8)$ & $29(85.3)$ & $9(69.2)$ & $14(87.5)$ & 0.39 \\
\hline ACEI's, n (\%) & $4(44.4)$ & $17(53.1)$ & $8(23.5)$ & $7(53.8)$ & $2(12.5)$ & 0.03 \\
\hline ARA's, n (\%) & $4(44.4)$ & $11(34.4)$ & $24(70.6)$ & $5(38.5)$ & $13(81.3)$ & 0.005 \\
\hline RMI, n (\%) & $6(66.7)$ & $19(59.4)$ & $25(73.5)$ & $7(53.8)$ & $12(75.0)$ & \\
\hline Diuretic, n (\%) & $6(66.7)$ & $13(40.6)$ & $18(52.9)$ & $10(76.9)$ & $7(43.8)$ & \\
\hline Nitrate, n (\%) & $4(44.4)$ & $10(31.3)$ & $16(47.1)$ & $10(76.9)$ & $5(31.3)$ & 0.06 \\
\hline
\end{tabular}

ACEI's $=$ Angiotensin converting enzyme inhibitors; ARA's= Angiotensin receptor antagonists; RMI= Receptor of Mineralocorticoids Inhibitor. Data are expressed as mean $\pm \mathrm{SD}$ or as $\mathrm{n}(\%)$ 
Patients in stage 5 had higher blood pressure than those in the other groups. Similarly, they had increased thickness of the ventricular septum and posterior wall. The functional class of patients was: NYHA-I, 55.4\%, NYHA II, 33.9\% and NYHA III-IV, $10.7 \%$. The last was more frequent in stages 1 and 4. (Table 1)

Angiotensin receptor antagonists were the drugs most often used in total population, while ACEI's were used less frequently in stage 5 .

Table 2. Anthropometric and biochemical data of patients with HF and CKD classified according to KDOQI stage

\begin{tabular}{|c|c|c|c|c|c|c|}
\hline Variable & $\begin{array}{l}\text { Stage } 1 \\
\text { GFR }(90-130 \mathrm{ml} / \mathrm{min}) \\
\mathrm{n}=9\end{array}$ & $\begin{array}{l}\text { Stage } 2 \\
\text { GFR }(60-89 \mathrm{ml} / \mathrm{min}) \\
n=32\end{array}$ & $\begin{array}{l}\text { Stage } 3 \\
\text { GFR }(30-59 \mathrm{ml} / \mathrm{min}) \\
n=34\end{array}$ & $\begin{array}{l}\text { Stage } 4 \\
\text { GFR }(15-29 \mathrm{ml} / \mathrm{min}) \\
\mathrm{n}=13\end{array}$ & $\begin{array}{l}\text { Stage } 5 \\
\text { GFR }(<15 \mathrm{ml} / \mathrm{min}) \\
\mathrm{n}=16\end{array}$ & $\mathbf{p}$ \\
\hline Weight (kg) & $86.4 \pm 20.8$ & $76.1 \pm 20.2$ & $70.3 \pm 17.6$ & $62.0 \pm 12.8$ & $63.5 \pm 9.8$ & 0.001 \\
\hline Height $(\mathrm{cm})$ & $164.1 \pm 8.8$ & $159.2 \pm 8.3$ & $160.1 \pm 11.5$ & $154.8 \pm 11.4$ & $158.9 \pm 10.3$ & 0.16 \\
\hline $\begin{array}{l}\text { Body mass index } \\
\left(\mathrm{kg} / \mathrm{m}^{2}\right)\end{array}$ & $31.9 \pm 7.1$ & $29.9 \pm 7.0$ & $28.0 \pm 5.6$ & $25.6 \pm 5.6$ & $25.5 \pm 4.3$ & 0.010 \\
\hline $\begin{array}{l}\text { Handgrip strength } \\
(\mathrm{Kg})\end{array}$ & $29.9 \pm 9.3$ & $27.2 \pm 8.7$ & $26.6 \pm 8.6$ & $22.7 \pm 8.7$ & $22.6 \pm 7.9$ & 0.06 \\
\hline $\begin{array}{l}\text { Arm circumference } \\
(\mathrm{cm})\end{array}$ & $32.3 \pm 6.5$ & $31.3 \pm 5.0$ & $30.3 \pm 3.8$ & $26.7 \pm 4.5$ & $26.9 \pm 3.2$ & 0.001 \\
\hline $\begin{array}{l}\text { Waist circumference } \\
(\mathrm{cm})\end{array}$ & $109.2 \pm 18.9$ & $99.6 \pm 17.2$ & $98.6 \pm 15.4$ & $93.1 \pm 10.2$ & $89.8 \pm 11.7$ & 0.009 \\
\hline $\begin{array}{l}\text { Hip circumference } \\
(\mathrm{cm})\end{array}$ & $107.8 \pm 15.7$ & $105.3 \pm 14.6$ & $102.9 \pm 12.8$ & $97.4 \pm 8.7$ & $97.0 \pm 12.0$ & 0.08 \\
\hline Impedance index & $0.81 \pm 0.03$ & $0.82 \pm 0.04$ & $0.83 \pm 0.03$ & $0.86 \pm 0.05$ & $0.85 \pm 0.03$ & $<0.0001$ \\
\hline Total body water (\%) & $50.0 \pm 8.6$ & $50.8 \pm 8.7$ & $54.3 \pm 7.1$ & $60.1 \pm 9.6$ & $58.6 \pm 8.6$ & 0.001 \\
\hline $\begin{array}{l}\text { Extracellular water } \\
(\%)\end{array}$ & $22.4 \pm 2.5$ & $23.1 \pm 2.9$ & $24.0 \pm 2.9$ & $27.2 \pm 3.4$ & $26.6 \pm 3.0$ & $<0.0001$ \\
\hline Phase angle, $\left({ }^{\circ}\right)$ & $5.4 \pm 1.1$ & $5.2 \pm 0.97$ & $5.1 \pm 1.3$ & $3.8 \pm 1.3$ & $4.2 \pm 1.2$ & $<0.0001$ \\
\hline $\begin{array}{l}\text { Phase angle }<4.2, n \\
(\%)\end{array}$ & $2(11.1)$ & $6(18.8)$ & $9(26.5)$ & $10(83.3)$ & $8(50)$ & $<0.0001$ \\
\hline Glucose (mg/dL) & $136.77 \pm 59.84$ & $114.96 \pm 32.44$ & $120.64 \pm 62.12$ & $124.23 \pm 67.54$ & $98.68 \pm 32.28$ & 0.161 \\
\hline Creatinine (mg/dL) & $0.9178 \pm .1106$ & $1.011 \pm .2067$ & $1.515 \pm .377$ & $2.515 \pm .9205$ & $10.289 \pm 6.3594$ & 0.000 \\
\hline Urea (mg/dL) & $37.07 \pm 14.26$ & $42.05 \pm 9.41$ & $67.53 \pm 25.65$ & $96.22 \pm 48.63$ & $136.86 \pm 50.16$ & 0.000 \\
\hline $\begin{array}{l}\text { Urea nitrogen } \\
(\mathrm{mg} / \mathrm{dL})\end{array}$ & $21.04 \pm 10.10$ & $19.65 \pm 4.39$ & $30.96 \pm 13.19$ & $44.96 \pm 22.72$ & $64.18 \pm 23.77$ & 0.000 \\
\hline Glomerular & & & & & & \\
\hline $\begin{array}{l}\text { Filtration Rate } \\
(\mathrm{mg} / \mathrm{dL})\end{array}$ & $106.91 \pm 11.54$ & $70.45 \pm 7.91$ & $45.12 \pm 9.91$ & $24.57 \pm 4.71$ & $7.63 \pm 3.96$ & 0.000 \\
\hline Albumin (g/dL) & $3.34 \pm .75$ & $4.23 \pm .57$ & $4.08 \pm .43$ & $3.57 \pm .66$ & $3.57 \pm .79$ & 0.003 \\
\hline Hemoglobin (g/dL) & $15.76 \pm 3.84$ & $13.78 \pm 2.52$ & $14.02 \pm 1.72$ & $11.18 \pm 2.00$ & $10.18 \pm 2.00$ & 0.000 \\
\hline Hematocrit (\%) & $47.88 \pm 12.27$ & $40.71 \pm 7.09$ & $41.80 \pm 4.81$ & $33.70 \pm 6.11$ & $30.00 \pm 5.97$ & 0.000 \\
\hline Sodium (mmol/L) & $138.44 \pm 4.97$ & $138.80 \pm 3.54$ & $138.72 \pm 3.54$ & $136.61 \pm 2.81$ & $138.62 \pm 3.61$ & 0.549 \\
\hline Potassium (mmol/L) & $4.31 \pm .51$ & $4.62 \pm .44$ & $4.88 \pm .51$ & $4.79 \pm .78$ & $4.99 \pm .93$ & 0.011 \\
\hline Chlorine $(\mathrm{mmol} / \mathrm{L})$ & $100.66 \pm 4.27$ & $104.03 \pm 3.6$ & $105.33 \pm 3.59$ & $103.07 \pm 3.14$ & $101.94 \pm 4.59$ & 0.013 \\
\hline Calcium $(\mathrm{mmol} / \mathrm{L})$ & $9.00 \pm .41$ & $9.55 \pm .74$ & $9.63 \pm .48$ & $8.62 \pm .61$ & $8.33 \pm 1.42$ & 0.000 \\
\hline $\begin{array}{l}\text { Phosphorus } \\
(\mathrm{mmol} / \mathrm{L})\end{array}$ & $3.88 \pm .51$ & $3.30 \pm .58$ & $3.36 \pm .62$ & $3.76 \pm .80$ & $5.27 \pm 1.9$ & 0.000 \\
\hline $\begin{array}{l}\text { Magnesium } \\
(\mathrm{mmol} / \mathrm{L})\end{array}$ & $1.76 \pm .20$ & $2.09 \pm .25$ & $1.93 \pm .25$ & $2.23 \pm .48$ & $2.34 \pm .39$ & 0.001 \\
\hline
\end{tabular}

Data are expressed as mean $\pm \mathrm{SD}$ or as $\mathrm{n}(\%)$

Anthropometric and biochemical data are presented in Table 2. They show that weight, BMI, handgrip strength, arm and waist circumference, were lower in stages 4 and 5 in comparison with 1-3 stages of CKD; in contrast, impedance index, percentage of total and extracellular water, were higher. These differences were statistically significant even after adjusting for age.

The phase angle was used as an indicator of risk of malnutrition, taking as a point of reference values $<4.2^{\circ}$. Of the total population $31.3 \%$ were at risk of malnutrition. The risk of malnutrition in higher with advancing stages, with the lowest prevalence in stage 1 with $11.1 \%$, up to stage 4 , with $83.3 \%$, decreasing in stage 5 to $50 \%$. (Table 2) Biochemical data are summarized as follows: in stage 1 were observed the higher glucose levels, while in stage 5, the levels were lower. Creatinine, urea and urea nitrogen, matched with KDOQI stage classification according to the GFR. As regards electrolytes, phosphorus was higher in stage 5, magnesium levels were lower in stage 1 compared with stages 2-5, and the remaining electrolytes were within normal parameters. 


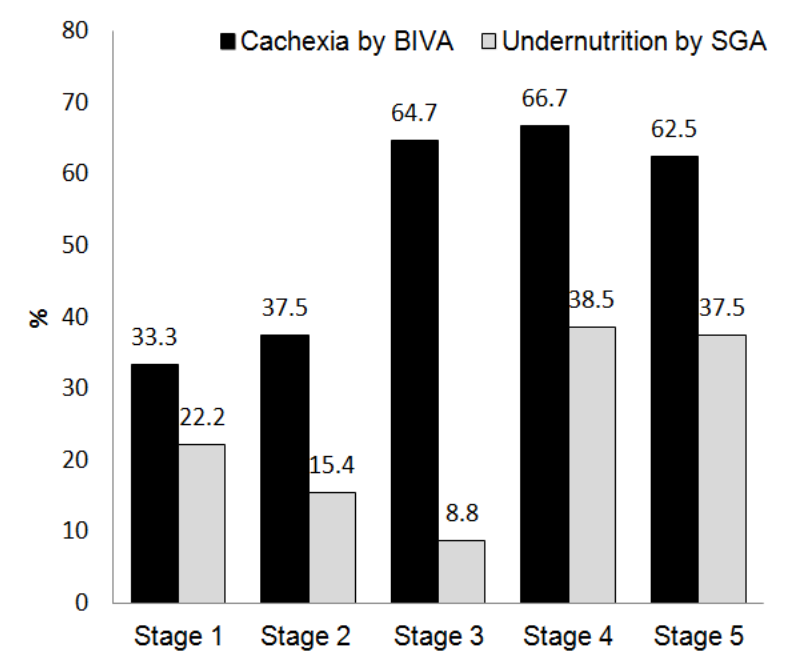

Figure 1. Body composition (BIVA) and nutritional status by SGA of patients with Heart Failure and Renal Disease classified according to KDOQI stage.

According to the results of body composition analysis, $53.6 \%$ showed cachexia, while $23.8 \%$ were obese and only $22.1 \%$ were within normal parameters of all patients. In the body composition analysis for each stage, where a greater prevalence of cachexia occurred in stages 3 to 5 . (Figure 1) The prevalence of obesity was lower in stage $3(14.7 \%)$ but higher in stage $1(33.3 \%)$. With respect to the nutritional status classification, according to the SGA score, $79.8 \%$ $(n=83)$ of the total sample had normal nutritional status, followed by $20.2 \%(n=21)$ with malnutrition. There was no presence of moderate and severe malnutrition in stages 1,2 and 3. However, moderate malnutrition was observed in stages 4 and 5 , with severe malnutrition only in stage 5 . The prevalence of malnutrition was higher in stage 4 and 5 compared with stages 1 to $3, p=0.06$. (Figure 1 )

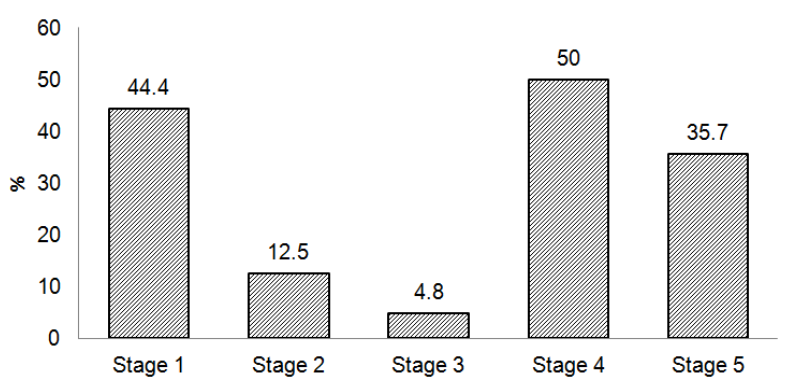

Figure 2. Frequency of hypoalbuminemia in patients with heart failure and renal disease classified according to KDOQI stage

Hypoalbuminemia was diagnosed in $23.5 \%(n=16)$ of subjects. It was most commonly in stage 4 and less in stage $3, \mathrm{p}=0.02$ (Figure 2). The prevalence of anemia was 50.6 $(\mathrm{n}=42)$ increasing with advancing stages: $100 \%$ in stage 5 and $13.3 \%$ in stage $1, \mathrm{p}<0.0001$. (Figure 3 )

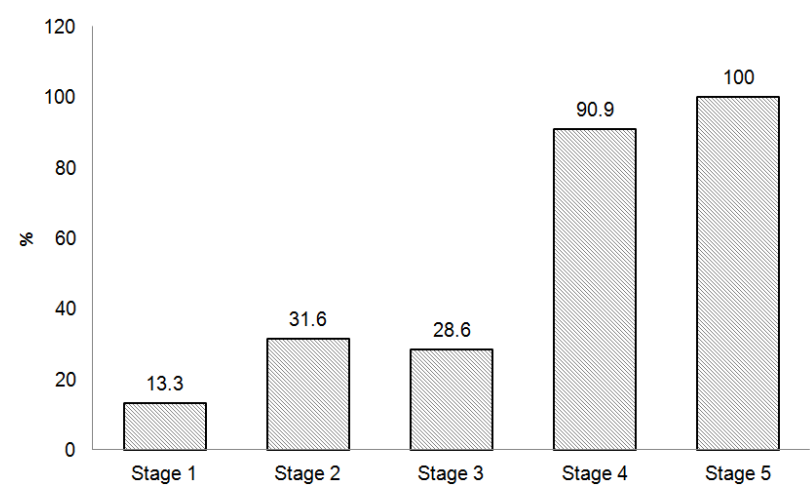

Figure 3. Prevalence of anemia in patients with heart failure and renal disease classified according to KDOQI stage

\section{Discussion}

Our results demonstrate the close relationship between worsening renal function and increased liquid retention, systolic and diastolic blood pressure, NYHA functional class III-IV, cardiac remodeling (hypertrophy), decreased handgrip strength, lower BMI, arm and waist circumference, lower phase angle and higher prevalence of anemia and cachexia in HF patients, regardless of age.

The protein-energy wasting present in cachexia is common in HF and CKD and is characterized by the protein loss (muscle mass) and energy (fat mass) reserves (20). This may be reflected in weight loss and body circumferences, as shown in BMI data and arm, waist and hip circumferences, which decrease as renal function progress. Another suitable parameter in the evaluation of muscle mass loss is handgrip strength, which aside from being a parameter for assessing the nutritional status is a predictor in $\mathrm{HF}$ and renal disease. Although the results are not statistically significant, it is known that the handgrip strength decreases in advanced stages of both kidney disease and heart failure. (21-23)

There is evidence of the relationship of phase angle and the nutritional status, similar to which Segall, et al. presented in 2009, where decreased phase angle values were associated with poor nutritional status in hemodialysis patients. (24) In another study, in heart failure patients, Colin-Ramirez, et al. found that a phase angle $<4.2^{\circ}$ as a parameter of malnutrition, was associated with poor prognosis in this kind of patient. In the present study we found that the frequency of patients with phase angle $<4.2^{\circ}$, was higher in stage 1 to stage 4 , improving slightly in stage 5 , which may be due to the implementation of the dialysis, meaning that the body composition evaluation allows better discrimination among the CKD stages.

In the present study there was a higher prevalence of cachexia in all stages, increasing with decreasing GFR. This, confirmed the results found for handgrip strength and phase angle, that a loss of muscle mass and nutritional status deterioration are more prevalent with advancing stages of CKD. It seems that the protein-energy wasting is due to stress imposed by the coexistence of advanced renal 
and heart disease. (22)

The diagnosis based on SGA, also confirms that the prevalence of malnutrition is higher in more severe states of CKD. However, the prevalence did not match the body composition data, perhaps because SGA is a method where malnutrition can be underestimated. (7)

Although hypoalbuminemia has been considered as part of malnutrition in HF and CKD patients, it could be also explained as volume overload, inflammation, proteinuria, renal disease and right heart failure. Indeed, its presence in overweight and obesity patients should be considered to reflect more than inappropriate food intake. (25) Moreover, hypoalbuminemia occurred more often in stages, 1, 4 and 5, and these results are consistent with the prevalence of right heart failure, but may also result from other different mechanisms that mentioned above.

Anemia, like other nutritional parameters evaluated in this research, was higher in more severe stage of CKD, and was found in $100 \%$ of cases in stage 5 . The prevalence of anemia in the literature is variable depending on the population studied, Souza, et al. (26) reported a prevalence of $55 \%$ in stage 5 , while Borges, et al. had similar results to those present study $100 \%$ of anemia in stage 5. (27)

Our study had some limitations, it included a small sample size of selected patients, and it was a cross-sectional, single-center study. These factors may limit the ability to generalize the results observed in this study. However, our findings are particularly encouraging and should serve as a basis for future investigations including larger samples, aimed at enhancing the evaluation of heart failure patients with chronic kidney disease.

\section{Conclusions}

The impairment of renal function was associated with water retention, higher systolic and diastolic blood pressure, NYHA functional class III-IV (stages 4 and 5), cardiac remodeling (hypertrophy), prevalence of anemia (stage 5) and cachexia (stages 3-5), plus SGA malnutrition (stage 4 and 5) in HF patients, and lower phase angle regardless of age.

HF and CKD deteriorate the nutritional status of patients and should be monitored by BIVA together by a multidisciplinary team.

\section{Conflicts of Interest Statement}

All authors declare that they have no conflict of interest

\section{Acknowledgements}

The authors would like to thank: Professors Piccoli A and Pastori from the Department of Medical and Surgical Sciences, University of Padova, Padova, Italy, 2002 for giving us BIVA software.

\section{References}

[1] Dries DL, Exner D V, Domanski MJ, Greenberg B, Stevenson LW. The prognostic implications of renal insufficiency in asymptomatic and symptomatic patients with left ventricular systolic dysfunction. J Am Coll Cardiol. 2000;35:681-689.

[2] De Silva R, Nikitin NP, Witte KK a, Rigby AS, Goode K, Bhandari $\mathrm{S}$, et al. Incidence of renal dysfunction over 6 months in patients with chronic heart failure due to left ventricular systolic dysfunction: contributing factors and relationship to prognosis. Eur Heart J [Internet]. 2006 Mar [cited 2013 Jun 6];27(5):569-81. Available from: http://www.ncbi.nlm.nih.gov/pubmed/16364971

[3] Jardim M das N, Costa HM da, Kopel L, Lage SG. Avaliação nutricional do cardiopata crítico em terapia de substituição renal: dificuldade diagnóstica. Rev Bras Ter Intensiva [Internet]. Revista Brasileira de Terapia Intensiva; 2009 Jun 1 [cited 2014 Jan 28];21(2):124-8. Available from: http://www.rbti.org.br/artigo/detalhes/0103507X-21-2-2

[4] Cheung WW, Paik KH, Mak RH. Inflammation and cachexia in chronic kidney disease. Pediatr Nephrol [Internet]. $2010 \mathrm{Apr}$ [cited 2013 Oct 16];25(4):711-24. Available http://www.ncbi.nlm.nih.gov/pubmed/20111974

[5] Bennett SJ, Welch JL, Eckert GJ, Oldridge NB, Murray MD. Nutrition in chronic heart failure with coexisting chronic kidney disease. J Cardiovasc Nurs [Internet]. 2006;21(1):56-62. Available from: http://www.ncbi.nlm.nih.gov/pubmed/16407738

[6] Piccoli A, Codognotto M, Piasentin P, Naso A. Combined evaluation of nutrition and hydration in dialysis patients with bioelectrical impedance vector analysis (BIVA). Clin Nutr [Internet]. 2013 [cited 2013 Oct 17]; Available from: http://www.sciencedirect.com/science/article/pii/S02615614 1300229X

[7] Yamauti AK, Ochiai ME, Bifulco PS, Araújo MA De, Alonso RR, Ribeiro HC, et al. Subjective Global Assessment of Nutritional Status in Cardiac Patients. Arch Med Res. 2006;87(6):707-12.

[8] Castillo-Martínez L, Colín-Ramírez E, Orea-Tejeda A, González Islas DG, Rodríguez García WD, Santillán Díaz C, et al. Cachexia assessed by bioimpedance vector analysis as a prognostic indicator in chronic stable heart failure patients. Nutrition [Internet]. 2012 Sep [cited 2013 Jul 2];28(9):88691. Available from: http://www.ncbi.nlm.nih.gov/pubmed/22480798

[9] Bellizzi V, Scalfi L, Terracciano V, De Nicola L, Minutolo R, Marra M, et al. Early changes in bioelectrical estimates of body composition in chronic kidney disease. J Am Soc Nephrol [Internet]. 2006 May 1 [cited 2013 Aug 27];17(5):1481-7. Available from: http://jasn.asnjournals.org/content/17/5/1481.full

[10] Dickstein K, Cohen-Solal A, Filippatos G, McMurray JJ V, Ponikowski P, Poole-Wilson PA, et al. ESC Guidelines for the diagnosis and treatment of acute and chronic heart failure 2008: the Task Force for the Diagnosis and Treatment of Acute and Chronic Heart Failure 2008 of the European Society of Cardiology. Developed in collaboration 
with the Heart. Eur Heart J [Internet]. 2008 Oct [cited 2013 May 22];29(19):2388-442. Available from: http://www.ncbi.nlm.nih.gov/pubmed/18799522

[11] Detsky AS, McLaughlin JR, Baker JP, Johnston N, Whittaker S, Mendelson RA JK. What is subjective global assessment of nutritional status. J Parenter Enter Nutr. 1987;11:8-13.

[12] Norman K, Stobäus N, Gonzalez MC, Schulzke J-D, Pirlich M. Hand grip strength: outcome predictor and marker of nutritional status. Clin Nutr [Internet]. Elsevier Ltd; 2011 May [cited 2013 May 31];30(2):135-42. Available from: http://www.ncbi.nlm.nih.gov/pubmed/21035927

[13] Lukaski H, Johnson P, Bolonchuk W, Lykken G. Assessment of fat-free mass using bioelectrical impedance measurements of the human body. Am J Clin Nutr [Internet]. 1985 Apr 1 [cited 2013 Oct 21];41(4):810-7. Available from: http://ajcn.nutrition.org/content/41/4/810.short

[14] Colín-Ramírez E, Castillo-Martínez L, Orea-Tejeda A, Vázquez-Durán $\mathrm{M}$, Rodríguez $\mathrm{AE}$, Keirns-Davis C. Bioelectrical impedance phase angle as a prognostic marker in chronic heart failure. Nutrition [Internet]. 2012 Sep [cited 2013 Jul 2];28(9):901-5. Available from: http://www.ncbi.nlm.nih.gov/pubmed/22465907

[15] Piccoli A, Rosell LDNJ. bioimpedancia en la práctica clínica. Nefrología. 2002;XXII(3):228-38.

[16] Piccoli A, Rossi B, Pillon L BG. A new method of monitoring body fluid varitation by impedance analysis.pdf. Kidney Int. 1994;46:534-9.

[17] Espinosa-Cuevas MA, Rivas-Rodríguez L, GonzálezMedina EC, Atilano-Carsi X, Miranda-Alatriste P C-RR. Vectores de impedancia bioeléctrica para la composición corporal en población mexicana. Rev Investig clínica. 2007;59(1):15-24.

[18] Levey AS. A More Accurate Method To Estimate Glomerular Filtration Rate from Serum Creatinine: A New Prediction Equation. Ann Intern Med [Internet]. American College of Physicians; 1999 Mar 16 [cited 2013 Oct 21];130(6):461. Available from: http://annals.org/article.aspx?articleid=712617

[19] Levey AS, Coresh J, Balk E, Kausz AT, Levin A, Steffes MW et al. National Kidney Foundation Practice Guidelines for Chronic Kidney Disease: Evaluation, classification, and stratification. Ann Intern Med. 2003;139:137-47.
[20] Jadeja YP, Kher V. Protein energy wasting in chronic kidney disease: An update with focus on nutritional interventions to improve outcomes. Indian $\mathrm{J}$ Endocrinol Metab [Internet]. 2012 Mar [cited $2013 \mathrm{Jul}$ 15];16(2):246-51. Available from: http://www.pubmedcentral.nih.gov/articlerender.fcgi?artid= $3313743 \&$ tool $=$ pmcentrez\&rendertype $=$ abstract

[21] Chang Y-T, Wu H-L, Guo H-R, Cheng Y-Y, Tseng C-C, Wang $\mathrm{M}-\mathrm{C}$, et al. Handgrip strength is an independent predictor of renal outcomes in patients with chronic kidney diseases. Nephrol Dial Transplant [Internet]. 2011 Nov [cited 2013 Jul 15];26(11):3588-95. Available from: http://www.ncbi.nlm.nih.gov/pubmed/21444362

[22] Izawa KP, Watanabe S, Osada N, Kasahara Y, Yokoyama H, Hiraki K, Morio Y, Yoshioka S, Oka K OK. Handgrip strength as a predictor of prognosis in Japanese patients with congestive heart failure. Eur J Cardiovasc Prev Rehabil. 2009;16:21-7.

[23] Cheung C-L, Nguyen U-SDT, Au E, Tan KCB, Kung AWC. Association of handgrip strength with chronic diseases and multimorbidity: A cross-sectional study. Age (Dordr) [Internet]. 2012 Feb 8 [cited 2013 Jun 3];1-13. Available from: http://www.pubmedcentral.nih.gov/articlerender.fcgi?artid= 3636411\&tool $=$ pmcentrez\&rendertype $=$ abstract

[24] Segall L, Mardare N-G, Ungureanu S, Busuioc M, Nistor I, Enache R, et al. Nutritional status evaluation and survival in haemodialysis patients in one centre from Romania. Nephrol Dial Transplant [Internet]. 2009 Aug [cited 2013 Jul 15];24(8):2536-40. Available from: http://www.ncbi.nlm.nih.gov/pubmed/19297358

[25] Hussein MF. Prognostic Significance of Serum Albumin Levels in Patients with Systolic Heart Failure. Iraqui Postgrad Med J. 2012;11(3):411-8.

[26] Souza WN De, Maria C, Araújo S De, Alves S, Moraes M De. Anemia , Renal Dysfunction and Malnutrition Associated with Heart Failure in Patients with Valvulopathy. Arq Bras Cardiol. 2010;94(6):745-9.

[27] Borges dos Reis JF, AM SF, Vieira Bitencourt A, Cerqueira B, Neves S, Kuwano AY, et al. Prevalencia de Anemia e Insuficiencia Renal en Portadores de Insuficiencia Cardiaca No Hospitalizados. Arq Bras Cardiol. 2009;9(3):262-8. 